Original Research Paper

\title{
Simple Fabrication and Characterization of Piezoelectric Nanogenerators from Cobalt-Doped Zinc Oxide Nanofibers
}

\author{
${ }^{1}$ Suyitno, ${ }^{1}$ Syamsul Hadi, ${ }^{2}$ Mohd Zainizan Sahdan, \\ ${ }^{2}$ Nafarizal Nayan, ${ }^{2}$ Hashim Saim, ${ }^{3}$ Lukman Nulhakim and ${ }^{1}$ Agung Tri Wijayanta \\ ${ }^{I}$ Department of Mechanical Engineering, Universitas Sebelas Maret, Surakarta, Indonesia \\ ${ }^{2}$ Microelectronic and Nanotechnology-Shamsuddin Research Centre, Universiti Tun Hussein Onn Malaysia, Malaysia \\ ${ }^{3}$ Department of Mechanical Engineering, Polytechnic of Indorama, Purwakarta, Indonesia
}

\author{
Article history \\ Received: 10-03-2017 \\ Revised: 01-06-2017 \\ Accepted: 25-07-2017 \\ Corresponding Author: \\ Suyitno \\ Department of Mechanical \\ Engineering, Universitas \\ Sebelas Maret, Surakarta, \\ Indonesia \\ E-mail: suyitno@uns.ac.id
}

\begin{abstract}
The ferromagnetic cobalt doped into Zinc Oxide $(\mathrm{ZnO})$ crystals is a promising method for enhancing the performance of PiezoelectricBased Nano Generators (PENGs). The study reports the characterization and testing PENGs which simply fabricated from cobalt-doped $\mathrm{ZnO}$ nanofibers (NFs) synthesized by electro spinning machine. The electro spinning processes were conducted at a flow rate of $4 \mu \mathrm{L} / \mathrm{min}$ and at various cobalt concentrations followed by sintering at a temperature of $500^{\circ} \mathrm{C}$. The X-Ray Diffraction (XRD) spectra demonstrate that the crystalline diameter of Co-doped ZnO NFs increased as the content of cobalt increased, up to a concentration of $9 \%$. Meanwhile, the maximum output voltage and power density of PENGs with Co-doped ZnO NFs were $221.6 \mathrm{mV}$ and $148.8 \mathrm{nW} / \mathrm{cm}^{2}$, respectively when the PENGs were subjected to a cyclic mechanical load of $0.5 \mathrm{~kg}$. Therefore, PENGs fabricated from Co-doped $\mathrm{ZnO} \mathrm{NFs}$ are challenging for the next generation of self-powered devices.
\end{abstract}

Keywords: Fibers, Cobalt, Doping, Zinc Oxide, Electro Spinning, Piezoelectric, Nanogenerator

\section{Introduction}

Piezoelectric Nanogenerators (PENGs) have been investigated by many studies because of their capability to harvest mechanical energy from human motions, finger taps and environment movements into electrical energy via piezoelectric materials. PENGs have also been employed in various devices including wireless sensors, self-powered equipments and electromechanical systems (Cho et al., 2017). The key issues in PENGs are the design and the materials used (Dagdeviren et al., 2016).

There are various materials having a noncentrosymmetric property exploited for PENGs. Among them, $\mathrm{ZnO}$ materials are very promising because of its abundant availability, environmental friendliness and high Curie temperature. Above the Curie temperature, a non-centrosymmetric crystal transforms into a centrosymmetric structure and both ferroelectric city and piezoelectricity disappear (Ubaidillah et al., 2013; Xing et al., 2015).

The piezoelectricity of materials was represented by the piezoelectric constant, $d_{33}$. The higher the piezoelectricity, the bigger the voltage is generated from the PENGs. ZnO Nanowires (NWs) have a slightly bigger piezoelectric constant $\mathrm{d}_{33}$ of $15 \mathrm{pm} / \mathrm{V}$ (Christian et al., 2016) than that of the bulk $\mathrm{ZnO}$ with $\mathrm{d}_{33}$ of $9.93 \mathrm{pm} / \mathrm{V}$ (Zhao et al., 2004). ZnO NWs have a piezoelectric constant ranging from 1 to $75 \mathrm{pm} / \mathrm{V}$ (Lee et al., 2012) depending on their morphology. Meanwhile, $\mathrm{ZnO}$ Nanobelts (NBs) have bigger $\mathrm{d}_{33}(14.3-26.7 \mathrm{pm} / \mathrm{V})$ than that of ZnO Thin Films (TFs) synthesized by sputtering deposition (14 pm/V) (Dagdeviren et al., 2013). However, the ZnO TFs deposited onto a Si substrate by pulsed laser ablation has a high piezoelectric constant of $49.7 \mathrm{pm} / \mathrm{V}$ (Qin et al., 2016a; 2016b) because it exhibited a preferred c-axis orientation. In addition, $\mathrm{ZnO}$ Nanorods (NRs) were reported have the $\mathrm{d}_{33}$ ranging from 4.41 to $11.8 \mathrm{pm} / \mathrm{V}$ (Tamvakos et al., 2015) for single crystal and they further reached a highest value of 26.7 $\mathrm{pm} / \mathrm{V}$ when measured for $\mathrm{ZnO} \mathrm{NBs}$ (Zhao et al., 2004). Therefore, the morphology of $\mathrm{ZnO}$ significantly affects to the piezoelectric property, $\mathrm{d}_{33}$.

It has also been revealed that doping has an important effect on both a structural and a piezoelectric constant of 
$\mathrm{ZnO}$. Piezoelectric constant evaluated for $\mathrm{ZnO}$ TFs doped with $\mathrm{Ni}, \mathrm{Cu}, \mathrm{Fe}$ and $\mathrm{Co}$ shows a variation in the $\mathrm{d}_{33}$ values ranging from 5 to $14 \mathrm{pm} / \mathrm{V}$ (Zamiri et al., 2016). A significant increase in $d_{33}$ values up to $110 \mathrm{pm} / \mathrm{V}$ has been reported for $\mathrm{V}$-doped $\mathrm{ZnO}$ TFs (Zamiri et al., 2016). Meanwhile, $\mathrm{Cr}$-doped $\mathrm{ZnO}$ NRs have a very small $\mathrm{d}_{33}$ value of $1.68 \mathrm{pm} / \mathrm{V}$ (Sinha et al., 2014). Besides, Europium-doped $\mathrm{ZnO}$ NRs have the mean $\mathrm{d}_{33}$ of 43.38 $\mathrm{pm} / \mathrm{V}$ (Yadav et al., 2016). Therefore, the morphology and doping play important role for enhancing the performance of PENGs based on $\mathrm{ZnO}$ nanomaterials. However, to the best of our knowledge, there are only few studies on the piezoelectric constant of cobaltdoped ZnO Nano Fibers (NFs) and used for PENGs.

PENGs with a hetero-junction material of Li-doped $\mathrm{Cu}_{2} \mathrm{O} / \mathrm{ZnO}$ produced a power of $52 \mu \mathrm{W}$ (Cho et al., 2017). The $\mathrm{Li}$-doped $\mathrm{Cu}_{2} \mathrm{O} / \mathrm{ZnO}$ synthesized by radio frequency magnetron sputtering was flexible and transparent. Moreover, PENGs with the $\mathrm{ZnO} \mathrm{TFs}$ deposited onto a Si substrate by pulsed laser ablation at a substrate temperature of $500^{\circ} \mathrm{C}$ generated a voltage, current and power of $95 \mathrm{mV}, 35 \mu \mathrm{A} / \mathrm{cm}^{2}$ and 5.1 $\mathrm{mW} / \mathrm{cm}^{2}$, respectively (Qin et al., 2016a; 2016b). The PENGs with Ga-doped ZnO NWs produced a higher voltage ranging from 120 to $560 \mathrm{mV}$ (Zhao et al., 2015b) if compared with undoped $\mathrm{ZnO} \mathrm{NWs}$ generated a lower voltage of up to $25 \mathrm{mV}$ (Wang et al., 2008). Meanwhile, PENGs fabricated from Al-doped ZnO NRs and NFs capable of generating a voltage up to $60 \mathrm{mV}$ (Fang and Kang, 2010) and $265.5 \mathrm{mV}$ (Suyitno et al., 2014b), respectively. However, the voltage and power density of PENGs with $\mathrm{ZnO}$ nanomaterials are still low (Ren et al., 2009; Kanjwal et al., 2011).

Among the aforementioned materials used for PENGs, the ZnO NFs are very interesting because NFs can be simply synthesized using a low cost electrospinning machine (He et al., 2008) with a good durability (Suyitno et al., 2014a). Unfortunately, ZnO NFs exploited for PENGs are still limited. Besides Al, $\mathrm{Ga}, \mathrm{Li}, \mathrm{Ni}, \mathrm{Cu}, \mathrm{Fe}$ and $\mathrm{Cr}$ doping; Co-doped $\mathrm{ZnO}$ NFs synthesized by electrospinning method is a promising for enhancing the properties of $\mathrm{ZnO}$-based piezoelectric materials fabricated for PENGs. There is a study reported that cobalt doping does not significantly affect their piezoelectric performance, although it induces the paramagnetic state and gives rise to new photoluminescence emission peaks because of small changes in the lattice parameters and no changes to crystal structures (Zhao et al., 2015a). However, cobalt doping into $\mathrm{ZnO}$ nanoparticles (NP) synthesized by a coprecipitation method decreased a crystallite size and changed the diamagnetic behavior of $\mathrm{ZnO}$ into ferromagnetic nature (Gandhi et al., 2014).
Meanwhile, another study reported that the lattice constants of the c-axis increased with increasing cobalt content up to $25 \%$ and decreased above $25 \%$ because of the solubility of cobalt exceeds a thermal equilibrium limit below $25 \%$ due to a no-equilibrium sol-gel process (Lee et al., 2002).

The aforementioned studies show that the effect of cobalt doping into $\mathrm{ZnO}$ materials is still controversy and need to be deeply investigated particularly for $\mathrm{ZnO}$ NFs synthesized by electrospinning method. Furthermore, the optimal concentration of Co doping into $\mathrm{ZnO} \mathrm{NFs}$ applied for PENGs has not been entirely studied and characterized. Therefore, we report here the simple fabrication and the characterization of PENGs from cobalt-doped zinc oxide fibres synthesized by electrospinning method. In addition, we evaluate also the influence of the cobalt content on the performance of PENGs simply fabricated from cobalt-doped $\mathrm{ZnO}$ NFs.

\section{Method}

\section{Fabrication PENGs}

PENGs were simply fabricated from Co-doped $\mathrm{ZnO}$ NFs, two electrodes and Polydimethylsiloxane (PDMS) polymer. The NFs were synthesized by electro spinning method (Suyitno et al., 2014b). To avoid the damage of NFs, the collector used in electro spinning method was aluminum plate and then subsequently used for electrode. Both electrodes were glued together with PDMS as show in Fig. 1.

\section{Synthesizing Co-Doped ZnO NFs}

The materials used for synthesizing the Co-doped $\mathrm{ZnO} \mathrm{NFs}$ were polyvinyl alcohol ([- $\left.\mathrm{CH}_{2} \mathrm{CHOH}-\right] \mathrm{n}, \mathrm{PVA}$, $72000 \mathrm{MW}$, Merck), zinc acetate dihydrate $\left(\mathrm{Zn}\left(\mathrm{C}_{2} \mathrm{H}_{3} \mathrm{O}_{2}\right)_{2} .2 \mathrm{H}_{2} \mathrm{O}, \mathrm{ZnAc}\right.$, Merck) and cobalt(II) acetate tetrahydrate $\left(\left(\mathrm{CH}_{3} \mathrm{COO}\right)_{2} \mathrm{Co} \cdot 4 \mathrm{H}_{2} \mathrm{O}, \mathrm{CoAc}\right.$, Merck) and used as received.

We first synthesized the PVA solution. The PVA was dissolved in purified water at a mass ratio of 1:10, stirred at a temperature of $70^{\circ} \mathrm{C}$ for $4 \mathrm{~h}$ and allowed to settle for $24 \mathrm{~h}$ at a temperature of $25^{\circ} \mathrm{C}$.

To synthesize the CoAc/ZnAc solution with a cobalt content of $8 \%, 0.32 \mathrm{~g}$ of CoAc, $4.0 \mathrm{~g}$ of $\mathrm{ZnAc}$ and $16 \mathrm{~g}$ of $\mathrm{H}_{2} \mathrm{O}$ were mixed and stirred by magnetic stirrer at a temperature of $70^{\circ} \mathrm{C}$ for $2 \mathrm{~h}$. Next, synthesizing the $\mathrm{CoAc} / \mathrm{ZnAc} / \mathrm{PVA}$ solution was conducted by mixing $1 \mathrm{~g}$ of the $\mathrm{CoAc} / \mathrm{ZnAc}$ solution with $5 \mathrm{~g}$ of PVA solution, stirred at a temperature of $70^{\circ} \mathrm{C}$ for $2 \mathrm{~h}$ and followed by settling for $24 \mathrm{~h}$ at a temperature of $25^{\circ} \mathrm{C}$. The aforementioned procedures were repeated for synthesizing the $\mathrm{CoAc} / \mathrm{ZnAc} / \mathrm{PVA}$ solution at a cobalt content of $4,6,8,10,12$ and $14 \%$. 


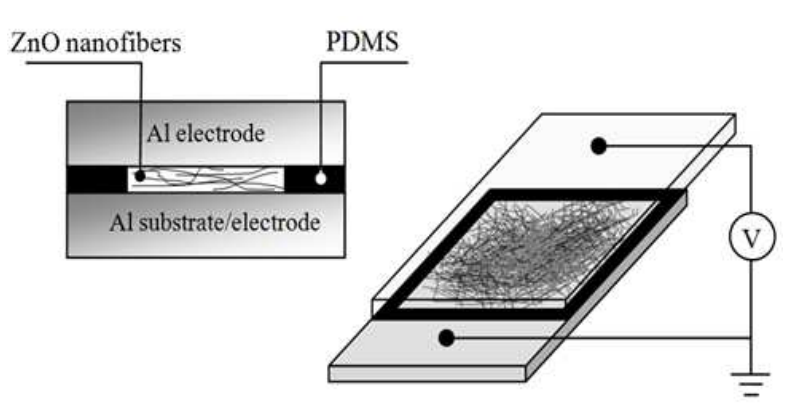

Fig. 1. PENGs configuration

In addition, $0.5 \mathrm{~mL}^{-1}$ of $\mathrm{CoAc} / \mathrm{ZnAc} / \mathrm{PVA}$ solution was poured in the syringe pump and electrospun in a horizontal electro spinning machine to produce the green fibers consisting of cobalt-doped ZnAc/PVA. The needle diameter of the syringe pump is $0.6 \mathrm{~mm}$. The distance between the tip needle of the syringe pump and the collector of an aluminum plate is $8 \mathrm{~cm}$. When a high voltage of approximately $15 \mathrm{kV}$ was applied, the solution was pulled out by electrostatic fields, attached on the surface of an aluminum collector plate and finally produced the non-woven green fibers. The green fibers were then sintered for $4 \mathrm{~h}$ at a temperature of $500^{\circ} \mathrm{C}$ (Yang et al., 2004) to remove PVA or organic materials and to growth the crystal of Co-doped $\mathrm{ZnO}$ fibers.

\section{Characterizing ZnO NFs and Testing PENGs}

The crystalline and morphological structures of Codoped $\mathrm{ZnO} \mathrm{NFs}$ were characterized using X-Ray Diffraction (XRD) and scanning electron microscopy (SEM, FEI: Inspect-S50). The analysis of SEM images was conducted by image software from Image $\mathrm{J}$.

The piezoelectric constant $d_{33}$ of Co-doped ZnO NFs was measured by $d_{33}$ Piezometer Systems from Piezotest Pte Ltd. Meanwhile, the PENGs were measured their output electric energy using an ADAM Advantech (series 4018) and software PCLS-Adam View 32. When measuring the output electric energy from NGs, the cyclic mechanical load of $0.5 \mathrm{~kg}$ was applied to represent the condition of a light finger tapping (Choi et al., 2010). The power of piezoelectric-based NGs was subsequently calculated from the output voltage generated by the variation of load resistance $(\Omega)$ (Chen et al., 2010), as following:

$P_{L}=\frac{1}{T} \int \frac{V_{o}(t)^{2}}{R_{L}} d t$

Where:

$P_{L}=$ The output power $(\mathrm{W})$

$T=$ The period (s)

$V_{o}=$ Is the output voltage $(\mathrm{V})$

$t=$ time (s)

$R_{L}=$ Is the electric load $(\Omega)$

\section{Results and Discussion}

\section{Structural Analysis}

Figure 2 shows the spectra of X-ray diffraction of the fibers of Co-doped $\mathrm{ZnO}$ NFs with cobalt content from 0 to $14 \%$. The sharp diffraction peaks show the good crystalline quality. The NFs tested showed similar diffraction patterns with the highest peak between 35.88 and $36.15^{\circ}$, which is the typical peak of zincite $\mathrm{ZnO}$ crystal (101). The diffraction patterns of Co-doped $\mathrm{ZnO}$ NFs corresponded to the data from JC-PDS standard card (PDF\#36-1451, space group P63 mc (186)).

Meanwhile, the shifts in the angle of diffraction peaks indicated the impurities of $\mathrm{ZnO}$ crystals caused by cobalt doping. Moreover, Fig. 2 shows also that clear sharp peaks coinciding with other impurities did not appear, suggesting that new phases did not arise and cobalt atoms were substituted within $\mathrm{ZnO}$ crystal lattices (Feng et al., 2009). At higher cobalt content, the peaks of diffraction appeared sharper which is in agreement with previous study (Nirmala and Anukaliani, 2011). In contrast, at a cobalt content of $14 \%$, the diffraction peaks were smaller and no peaks of cobalt compounds or cobalt existed, indicating the crystallization process was inhibited by means of impurity atoms.

Meanwhile, the crystalline diameter of cobalt-doped $\mathrm{ZnO}$ fibers was calculated using the Debye-Scherrer equation (Pongwan et al., 2012; Asikuzun et al., 2015):

$$
D=\frac{k \lambda}{B \cos \theta}
$$

Where:

$D=$ The crystalline diameter

$\lambda=$ The wavelength of X-ray $(\mathrm{CuK} \alpha=0.15406 \mathrm{~nm})$

$k=$ The constant $(0.9)$

$\theta=$ The diffraction angle

$B=$ The full width at half maximum.

Table 1 shows that the crystalline diameter of Codoped ZnO NFs were influenced by the concentration of cobalt. The corresponding crystalline diameter of Co-doped $\mathrm{ZnO}$ NFs increased by almost twice at a cobalt concentration of $9 \%$, which declined as the cobalt content further increased. The increase of grain size at a certain concentration of doping cobalt was also revealed from previous studies (Lee et al. 2002; Bahadur et al., 2010; Benramache et al., 2013; Gandhi et al., 2014; Asikuzun et al., 2015). Therefore, the previous study from (Zhao et al., 2015a) stating that cobalt doping does not significantly affect the lattice parameters and no changes to crystal structures is misleading within the synthesis of Co-doped $\mathrm{ZnO}$ NFs by the electrospinning machine. 
Furthermore, the crystalline diameter of Co-doped ZnO NFs varied ranging from 9.0 to $17.7 \mathrm{~nm}$. Doping cobalt at a concentration higher than $9 \%$ affected the decrease of the crystalline diameter because more cores were formed during the crystallization process (Lee et al., 2008).

Meanwhile, Fig. 3 shows the SEM images of the Codoped $\mathrm{ZnO}$ NFs at a magnification of $50,000 \times$. It can be observed that the fibers are randomly arranged. As shown in Table 2, the diameter of the fibres increased as the cobalt content increased up to a concentration of $9 \%$. The average diameter of the Co-doped ZnO NFs ranged from 87 to $133 \mathrm{~nm}$.

\section{Performance of PENGs from Co-Doped ZnO NFs}

The piezoelectric constant of Co-doped ZnO NFs has been measured and shown in Table 3 . There is a slight increase of $d_{33}$ as increasing concentration of doping Co up to $9-10 \%$. The $d_{33}$ values of Co-doped $\mathrm{ZnO}$ NFs ranging from 3.7 to $4.1 \mathrm{pm} / \mathrm{V}$ which is comparable with that of $\mathrm{ZnO} \mathrm{NRs}$ ranging from 4.41 to $11.8 \mathrm{pm} / \mathrm{V}$ (Tamvakos et al., 2015) and a bit higher than that of Crdoped ZnO NRs (1.68 pm/V) (Sinha et al., 2014).

Meanwhile, testing performance of NGs was conducted by applying the cyclic mechanical load of 0.5 $\mathrm{kg}$ every $3 \mathrm{sec}$. When the c-axis of cobalt-doped $\mathrm{ZnO}$ fibers was under the applied deformation, a piezoelectric field was created along fibers, which drive the electrons flowing in the external circuit.

Figure 4 shows the output voltage $(\mathrm{mV})$ produced from PENGs. Meanwhile, Fig. 5 shows the output power (nW) of PENGs. The maximum power and the maximum voltage produced by the PENGs can be seen in Table 4.

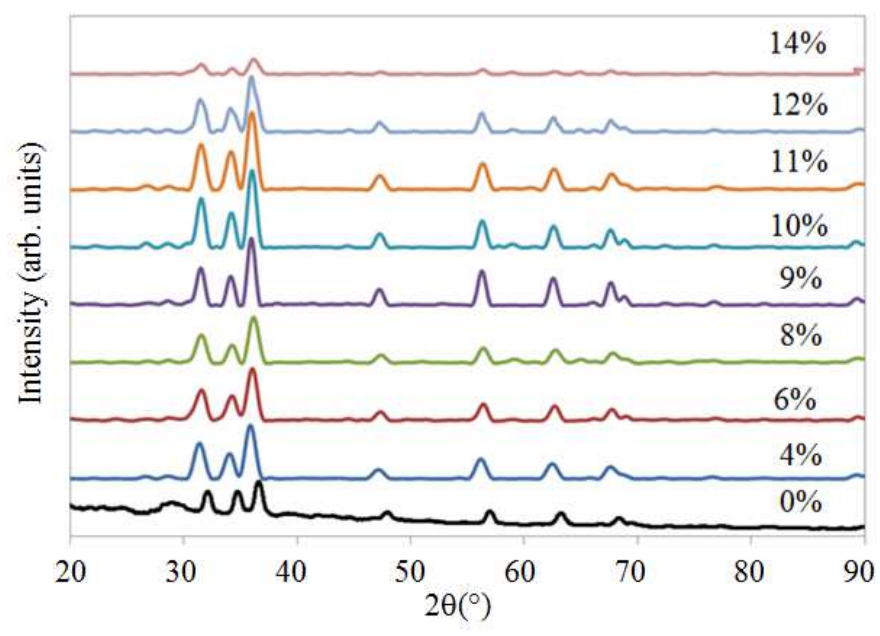

Fig. 2. X-ray diffraction patterns of cobalt-doped $\mathrm{ZnO}$ fibers

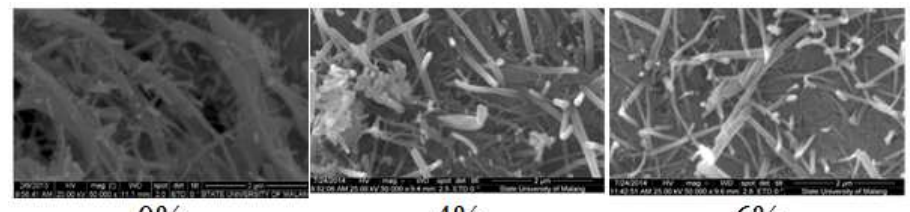

$0 \%$

$4 \%$

$6 \%$
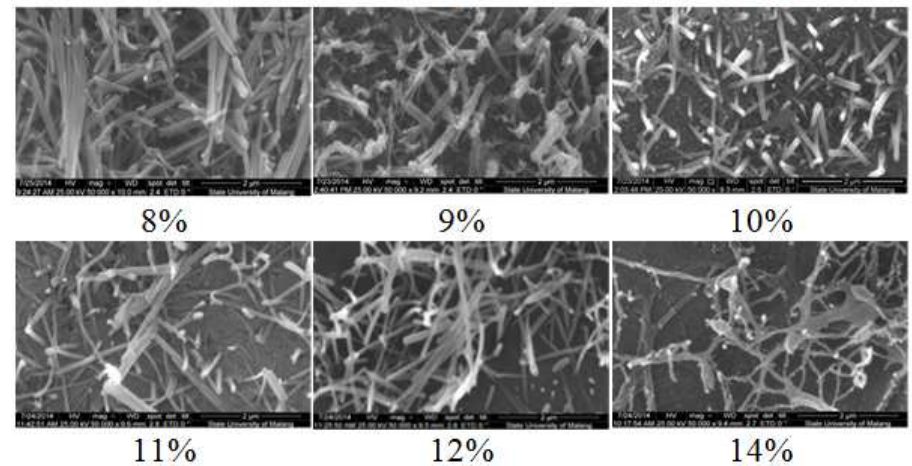

Fig. 3. SEM images of cobalt-doped $\mathrm{ZnO}$ fibers 


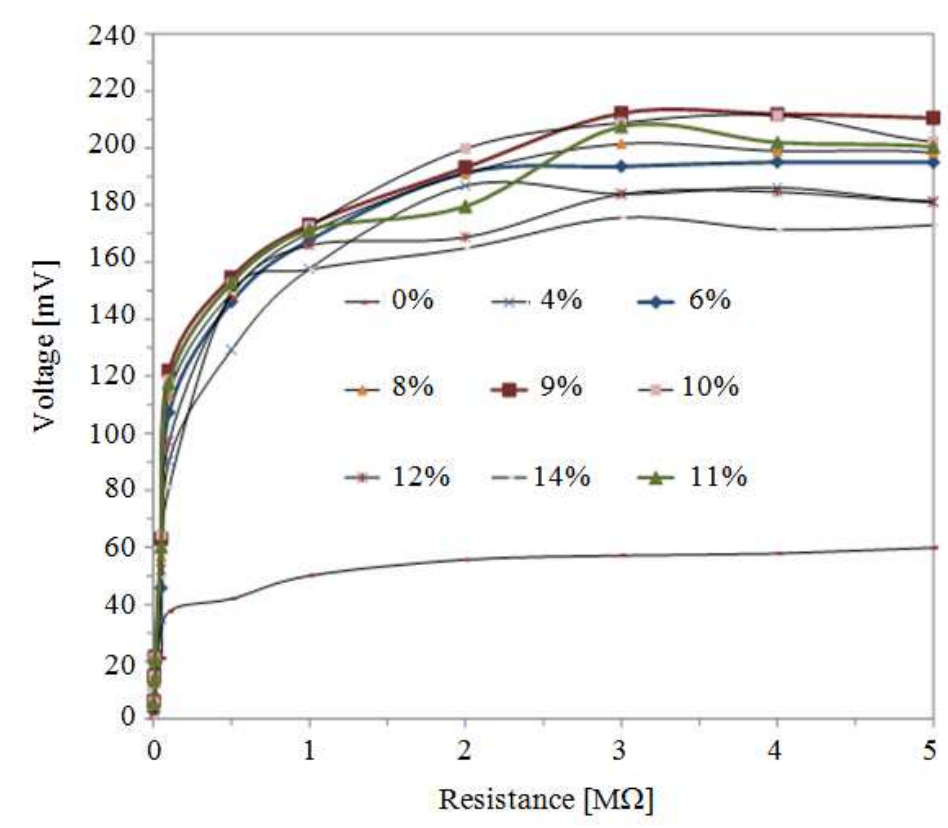

Fig. 4. Output voltage of PENGs from Co-doped ZnO NFs at various concentrations of cobalt

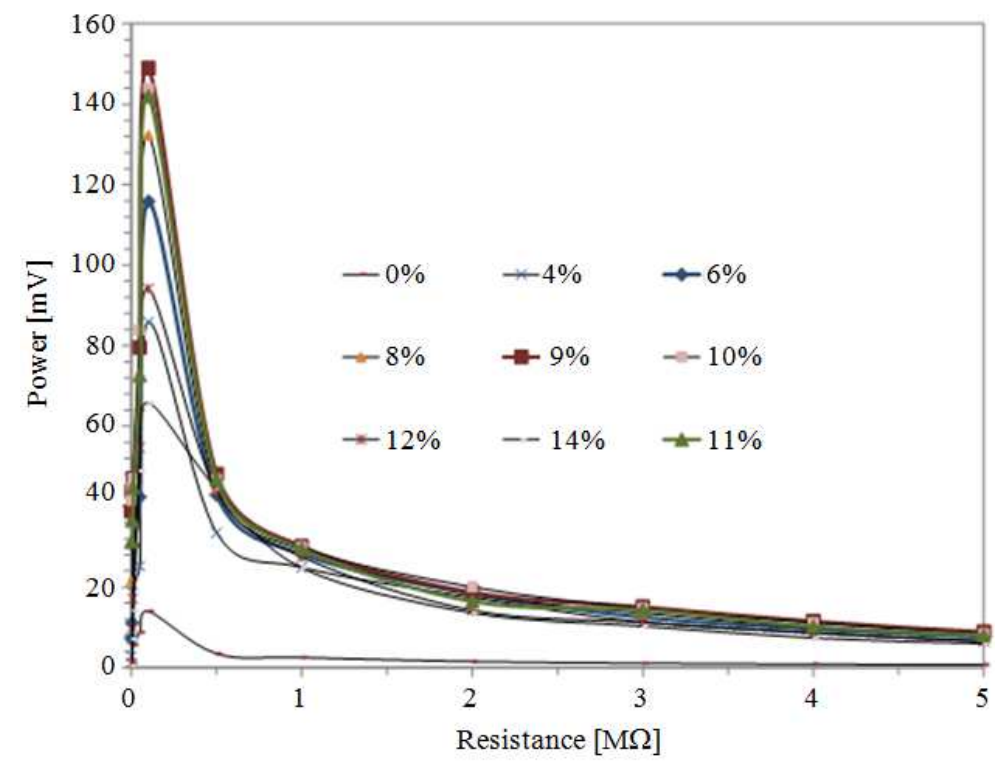

Fig. 5. Output power of PENGs from Co-doped ZnO NFs at various concentration of cobalt

Table 1. Crystalline diameter and crystallinity of cobalt-doped $\mathrm{ZnO}$ fibers

\begin{tabular}{lllc}
\hline Cobalt concentration & 2 teta & FWHM & Crystalline diameter $(\mathrm{nm})$ \\
\hline $0 \%$ & 35.886 & 0.933 & 9.0 \\
$4 \%$ & 35.880 & 0.888 & 9.4 \\
$6 \%$ & 36.148 & 0.851 & 9.8 \\
$8 \%$ & 36.119 & 0.746 & 11.2 \\
$9 \%$ & 35.934 & 0.471 & 17.7 \\
$10 \%$ & 36.060 & 0.603 & 13.9 \\
$11 \%$ & 36.013 & 0.633 & 13.2 \\
$12 \%$ & 36.061 & 0.742 & 11.3 \\
$14 \%$ & 36.151 & 0.808 & 10.3 \\
\hline
\end{tabular}


Table 2. Diameter of cobalt-doped $\mathrm{ZnO}$ fibers

Doping concentration (\%)

\begin{tabular}{|c|c|c|c|c|c|c|c|c|c|}
\hline \multirow[b]{2}{*}{ Fiber diameter $(\mathrm{nm})$} & \\
\hline & 0 & 4 & 6 & 8 & 9 & 10 & 11 & 12 & 14 \\
\hline Maximum & 283 & 169 & 204 & 208 & 304 & 202 & 199 & 164 & 250 \\
\hline Minimum & 42 & 39 & 37 & 40 & 33 & 50 & 47 & 26 & 37 \\
\hline Mean & 91 & 93 & 96 & 110 & 133 & 102 & 88 & 87 & 87 \\
\hline Standard deviation & 50 & 40 & 39 & 42 & 77 & 35 & 32 & 31 & 52 \\
\hline
\end{tabular}

Table 3. Piezoelectric constant, $\mathrm{d}_{33}$, of Co-doped ZnO NFs

\begin{tabular}{lc}
\hline Cobalt concentration & $\mathrm{d}_{\mathrm{ss}}(\mathrm{pm} / \mathrm{V})$ \\
\hline $0 \%$ & 3.7 \\
$4 \%$ & 3.7 \\
$6 \%$ & 3.8 \\
$8 \%$ & 3.9 \\
$9 \%$ & 4.1 \\
$10 \%$ & 4.1 \\
$11 \%$ & 4.0 \\
$12 \%$ & 4.0 \\
$14 \%$ & 3.9 \\
\hline
\end{tabular}

Table 4. Maximum power and voltage produced by the piezoelectric-based NGs

\begin{tabular}{|c|c|c|c|c|c|c|c|c|c|c|}
\hline \multirow[b]{2}{*}{ Performance } & \multicolumn{10}{|c|}{ Cobalt concentration } \\
\hline & $0 \%$ & $2 \%$ & $4 \%$ & $6 \%$ & $8 \%$ & $9 \%$ & $10 \%$ & $11 \%$ & $12 \%$ & $14 \%$ \\
\hline Max voltage $[\mathrm{mV}]$ & 64.2 & 180.2 & 189.9 & 205.3 & 214.1 & 221.6 & 220.6 & 218.9 & 201.9 & 198.1 \\
\hline Max power [nW] & 14.0 & 42.9 & 85.9 & 115.8 & 132.4 & 148.9 & 144.0 & 142.0 & 94.2 & 65.7 \\
\hline
\end{tabular}

Piezoelectric material is materials applied loads produces electricity. At a cyclic mechanical load of 0.5 $\mathrm{kg}$, the output voltage generated by PENGs with Codoped $\mathrm{ZnO}$ NFs was influenced by the resistance loads. The output voltage generated from PENGs increased as the concentration of cobalt doping increased. The sharp increase of output voltage was generated when the resistance load increased up to $1 \mathrm{k} \Omega$, followed with slight increase at higher resistance load than $1 \mathrm{k} \Omega$. At doping cobalt about $9 \%$, the output voltage generated increased nearly 3.45 times than that produced by PENGs without doping cobalt.

The maximum output voltage of PENGs was 221.6 $\mathrm{mV}$. The output voltage of the PENGs with Co-doped $\mathrm{ZnO}$ NFs was higher when compared with previous study (Choi et al., 2010). PENGs with ZnO TFs generated voltages of 20 and $60 \mathrm{mV}$ at a mechanical load of 0.4 and $1 \mathrm{~kg}$, respectively. In contrast, the PENGs based on $\mathrm{NiO} / \mathrm{ZnO} \mathrm{NWs}$ were capable to generate a voltage of $388 \mathrm{mV}$ (Qu et al., 2016) because ZnO NWs were vertically grown. Meanwhile, by ferrous doping, PENGs with the vertical $\mathrm{ZnO}$ NWs generated a voltage up to $850 \mathrm{mV}$ (Zhu et al., 2015).

In addition, the output power generated by PENGs with Co-doped $\mathrm{ZnO}$ NFs increased as the cobalt concentration increased up to $9 \%$. As previously discussed, the synthesized NFs demonstrated the highest crystallinity at a cobalt concentration at $9 \%$. The maximum output power of PENGs, $148.9 \mathrm{nW}$, was generated when the cobalt concentration of $9 \%$ as shown in Fig. 5 corresponding to an output current of $1.2 \mu \mathrm{A}$. The current generated from the PENGs with Co-doped $\mathrm{ZnO}$ NFs was greater than that from the PENGs with $\mathrm{ZnO} \mathrm{NWs} / \mathrm{PZT}$ (lead zirconate titanate) hetero-junction, namely 270 nA (Im-Jun et al., 2013) and with NiO-ZnO hetero-junction, namely $40 \mathrm{nA} / \mathrm{cm}^{2}$ (Yin et al., 2015). Moreover, the maximum output power was equivalent to a power density of $148.8 \mathrm{nW} / \mathrm{cm}^{2}$. The power density produced by PENGs with Co-doped ZnO NFs was greater than the achieved by a previous study, namely $51.7 \mathrm{nW} / \mathrm{cm}^{2}$ (Suyitno et al., 2014b).

\section{Conclusion}

PENGs were simply fabricated from Co-doped $\mathrm{ZnO}$ NFs and successfully tested. The greatest crystallinity was achieved by cobalt doping at a concentration of $9 \%$. Furthermore, the cobalt concentration has doubled the crystalline diameter of ZnO NFs. In contrast, the cobalt content in the $\mathrm{ZnO} \mathrm{NFs}$ significantly influenced the output voltage and output power of PENGs. The maximum output voltage of PENGs with Co-doped $\mathrm{ZnO}$ $\mathrm{NFs}$ is $221.6 \mathrm{mV}$. Meanwhile, the maximum output power, which is equivalent to the power density of 148.8 $\mathrm{nW} / \mathrm{cm}^{2}$, was achieved when PENGs were subjected to a cyclic mechanical load of $0.5 \mathrm{~kg}$. The PENGs fabricated from Co-doped $\mathrm{ZnO}$ NFs generated high power density values and are interesting candidates for employing in self-power devices. 


\section{Acknowledgement}

The authors would like to acknowledge the support from the Rector of Universitas Sebelas Maret, LPPM UNS and the Indonesia Endowment Fund for Education (LPDP) for supporting the project activities.

\section{Funding Information}

This project is funded by Ministry of Research, Technology and Higher Education of the Republic of Indonesia and the Rector of Universitas Sebelas Maret through the Research Grant (623/UN27.21/PP/2017 and 873/UN27.21/PP/2017).

\section{Author's Contributions}

Suyitno: Principal investigator, reviewed the significant content and corresponding author.

Syamsul Hadi: Supervised the experiments, provided the exhaustive data and interpretated the data.

Mohd Zainizan Sahdan: Reviewed the related previous works, XRD analysis and checked the gramatical errors.

Nafarizal Nayan: Reviewed the logical writing, SEM analysis and checked the gramatical errors.

Hashim Saim: Reviewed the comprehensively discussion.

Agung Tri Wijayanta: Supervised the experiments, checked tables and figures and interpretated the data.

Lukman Nulhakim: Drafted the manuscripts and conducted the experiments of the performance of pengs.

\section{Ethics}

The present work is not published in its present form in any journal or will not be published in any journal.

\section{References}

Asikuzun, E., A. Donmez, L. Arda, O. Cakiroglu and O. Ozturk et al., 2015. Structural and mechanical properties of $(\mathrm{Co} / \mathrm{Mg})$ Co-Doped Nano $\mathrm{ZnO}$. Ceram. Int., 41: 6326-6334.

DOI: $10.1016 /$ j.ceramint.2015.01.061

Bahadur, N., A.K. Srivastava, S. Kumara, M. Deepa and B. Nag, 2010. Influence of cobalt doping on the crystalline structure, optical and mechanical properties of $\mathrm{ZnO}$ thin films. Thin Solid Films, 518: 5257-5264. DOI: 10.1016/j.tsf.2010.04.113

Benramache, S., B. Benhaoua and H. Bentrah, 2013. Preparation of transparent, conductive $\mathrm{ZnO}$ :Co and $\mathrm{ZnO}$ : In thin films by ultrasonic spray method. J. Nanostructure Chem., 3: 1-7.

Chen, X., S. Xu, N. Yao and Y. Shi, 2010. $1.6 \mathrm{~V}$ Nanogenerator for mechanical energy harvesting using PZT Nanofibers. Nano Lett., 10: 2133-2137. DOI: $10.1021 / \mathrm{nl} 100812 \mathrm{k}$
Cho, K.S., D.H. Kim, Y.H. Kim, J. Nah and H.K. Kim, 2017. Li-doped $\mathrm{Cu}_{2} \mathrm{O} / \mathrm{ZnO}$ heterojunction for flexible and semi-transparent piezoelectric nanogenerators. Ceram. Int., 43: 2279-2287. DOI: 10.1016/j.ceramint.2016.10.208

Choi, D., K.Y. Lee, K.H. Lee, E.S. Kim and T.S. Kim et al., 2010. Piezoelectric touch-sensitive flexible hybrid energy harvesting nano architectures. Nanotechnology, 21: 405-503.

Christian, B., J. Volk, I.E. Lukàcs, E. Sautieff and C. Sturm et al., 2016. Piezo-force and vibration analysis of $\mathrm{ZnO}$ nanowire arrays for sensor application. Proc. Eng., 168: 1192-1195. DOI: 10.1016/j.proeng.2016.11.406

Dagdeviren, C., S.W. Hwang, Y. Su, S. Kim and H. Cheng et al., 2013. Transient, biocompatible electronics and energy harvesters based on $\mathrm{ZnO}$. Small, 9: 3398-3404. DOI: 10.1002/smll.201300146

Dagdeviren, C., P. Joe, O.L. Tuzman, K.I. Park and K.J. Lee et al., 2016. Recent progress in flexible and stretchable piezoelectric devices for mechanical energy harvesting, sensing and actuation. Extreme Mechan. Lett., 9, Part, 1: 269-281.

Fang, T.H. and S.H. Kang, 2010. Physical properties of $\mathrm{ZnO}: \mathrm{Al}$ nanorods for piezoelectric nano generator application. Curr. Nanosci., 6: 505-511. DOI: $10.2174 / 157341310797574961$

Feng, Z.S., Y.C. Hong, L. Qi, S.F. Qi and W.J. Guo et al., 2009. Cluster-assembled cobalt doped $\mathrm{ZnO}$ nanostructured film prepared by low energy cluster beam deposition. Trans. Nonferrous Met. Soc. China, 19: 1450-1453. DOI: 10.1016/S1003-6326(09)60049-2

Gandhi, V., R. Ganesan, H.H.A. Syedahamed and M. Thaiyan, 2014. Effect of cobalt doping on structural, optical and magnetic properties of $\mathrm{ZnO}$ nanoparticles synthesized by coprecipitation method. J. Phys. Chem. C, 118: 9715-9725. DOI: $10.1021 / \mathrm{jp} 411848 \mathrm{t}$

He, J.H., Y. Liu, L.F. Mo, Y.Q. Wan and L. Xu, 2008. Electrospun nanofibres and their applications. iSmithers, United Kingdom.

Kanjwal, M.A., F.A. Sheikh and N.A.M. Barakat, 2011. Co3o4-ZnO nanofiber their properties. J. Nanoeng. Nanomanuf., 1: 196-202. DOI: $10.1166 /$ jnan.2011.1016

Lee, D.Y., J.E. Cho, N.I. Cho, M.H. Lee and S.J. Lee et al., 2008. Characterization of electrospun aluminiumdoped zinc oxide nanofibers. Thin Solid Film, 517: 1262-1267. DOI: 10.1016/j.tsf.2008.05.027

Lee, H.J., S.Y. Jeong, C.R. Cho and C.H. Park, 2002. Study of diluted magnetic semiconductor: Codoped ZnO. Applied Phys. Lett., 81: 4020-4022. DOI: $10.1063 / 1.1517405$

Lee, H., J. Park, S.A. Han, D. Lee and K.B. Kim et al., 2012. The stress-dependent piezoelectric coefficient of $\mathrm{ZnO}$ wire measured by piezoresponse force microscopy. Scripta Materialia, 66: 101-104. DOI: $10.1016 /$ j.scriptamat.2011.10.013 
Nirmala, M. and A. Anukaliani, 2011. Characterization of undoped and Codoped $\mathrm{ZnO}$ nanoparticles synthesized by DC thermal plasma method. Phys. B Condensed Matt., 406: 911-915. DOI: $10.1016 /$ j.physb.2010.12.026

Im-Jun, N., J. Dae-Yong, S. Lee, S.H. Kim and J.W. Cho et al., 2013. Enhanced charge generation of the $\mathrm{ZnO}$ nanowires/PZT hetero-junction based nanogenerator. Microelectr. Eng., 110: 282-287. DOI: $10.1016 /$ j.mee.2013.01.058

Pongwan, P., B. Inceesungvorn and K. Wetchakun, 2012. Highly efficient visible-light-induced photocatalytic activity of fe-doped $\mathrm{TiO}_{2}$ Nanoparticles. Eng. J., 16: 143-151. DOI: 10.4186/ej.2012.16.3.143

Qin, W., T. Li, Y. Li, J. Qiu and X. Ma et al., 2016a. A high power $\mathrm{ZnO}$ thin film piezoelectric generator. Applied Surface Sci., 364: 670-675.

Qin, W.W., Y.T. Li, T. Li, J.W. Qiu and X.J. Ma et al., 2016b. Microstructure-related piezoelectric properties of a $\mathrm{ZnO}$ film grown on a Si substrate. Ceram. Int., 42: 16927-16934.

DOI: 10.1016/j.ceramint.2016.07.192

Qu, Z., Y. Fu, B. Yu, P. Deng and L. Xing et al., 2016. High and fast $\mathrm{H} 2 \mathrm{~S}$ response of $\mathrm{NiO} / \mathrm{ZnO}$ nanowire nanogenerator as a self-powered gas sensor. Sensors Actuators B Chem., 222: 78-86. DOI: 10.1016/j.snb.2015.08.058

Ren, H., Y. Ding, Y. Jiang, F. Xu and Z. Long et al., 2009. Synthesis and Properties of $\mathrm{ZnO}$ Nanofibers Prepared by Electrospinning. J. Sol-Gel Sci. Technol., 52: 287-290.

Sinha, N., G. Ray, S. Godara, M.K. Gupta and B. Kumar, 2014. Enhanced piezoelectric output voltage and Ohmic behavior in Cr-doped $\mathrm{ZnO}$ nanorods. Mater. Res. Bull., 59: 267-271. DOI: 10.1016/j.materresbull.2014.07.032

Suyitno, S., S. Huda, Z. Arifin and S. Hadi, 2014a. Repeatability, reproducibility and durability of zinc oxide fibre-based nanogenerator synthesized by simple electrospinning machine. Adv. Sci. Lett., 20: 2299-2303. DOI: 10.1166/asl.2014.5719

Suyitno, S., A. Purwanto, R.L.L.G. Hidayat, I. Sholahudin and M. Yusuf et al., 2014b. Fabrication and characterization of zinc oxide-based electrospun nanofibers for mechanical energy harvesting. J. Nanotechnol. Eng. Med. DOI: 10.1115/1.4027447

Tamvakos, D., S. Lepadatu, V.A. Antohe, A. Tamvakos and P.M. Weaver et al., 2015. Piezoelectric properties of template-free electrochemically grown $\mathrm{ZnO}$ nanorod arrays. Applied Surface Sci., 356: 1214-1220. DOI: 10.1016/j.apsusc.2015.08.187
Ubaidillah, S., W.E. Juwana, B. Prabandono and A. Purwanto, 2013. Characteristics of zinc oxide nanorods synthesized by low power DC thermal plasma. Scientia Iranica, 20: 2348-2355.

Wang, Z.L., X. Wang, J. Song, J. Liu and Y. Gao, 2008. Piezoelectric nanogenerators for selfpowered nanodevices. IEEE Comput. Society, 7: 49-55. DOI: 10.1109/MPRV.2008.14

Xing, H., P. Huang, C. Zhang, D. Li and Y. Zhang et al., 2015. Two new high Curie temperature piezoelectric ceramics. Mater. Lett., 160: 38-40. DOI: $10.1016 /$ j.matlet.2015.07.073

Yadav, H., N. Sinha, S. Goel and B. Kumar. 2016. Eudoped $\mathrm{ZnO}$ nanoparticles for dielectric, ferroelectric and piezoelectric applications. J. Alloys Compounds, 689: 333-341. DOI: 10.1016/j.jallcom.2016.07.329

Yang, X., C. Shao, H. Guan, X. Li and J. Gong, 2004. Preparation and characterization of $\mathrm{ZnO}$ nanofibers by using electrospun PVA/Zinc acetate composite fiber as precursor. Inorganic Chem. Commun., 7: 176-178. DOI: 10.1016/j.inoche.2003.10.035

Yin, B., Y. Qiu, H. Zhang, J. Lei and Y. Chang et al., 2015. Piezoelectric performance enhancement of $\mathrm{ZnO}$ flexible nanogenerator by a $\mathrm{NiO}-\mathrm{ZnO}$ p-n junction formation. Nano Energy, 14: 95-101. DOI: 10.1016/j.nanoen.2015.01.032

Zamiri, R., A. Kaushal, A. Rebelo, B. Singh and I. Bdikin et al., 2016. Enhanced local piezoelectric response in the erbium-doped $\mathrm{ZnO}$ nanostructures prepared by wet chemical synthesis. J. Asian Ceramic Societies Press. DOI: 10.1016/j.jascer.2016.10.002

Zhao, L.L., J.Y. Wang, X.L. Wang, Z.X. Cheng and J. Wang et al., 2015a. Cobalt doping effects on photoluminescence, Raman scattering, crystal structure and magnetic and piezoelectric properties in $\mathrm{ZnO}$ single crystals grown from molten hydrous $\mathrm{LiOH}$ and $\mathrm{NaOH}$ solutions. J. Alloys Compounds, 628: 303-307. DOI: 10.1016/j.jallcom.2014.12.148

Zhao, T., Y. Fu, Y. Zhao, L. Xing and X. Xue, 2015b. Ga-doped $\mathrm{ZnO}$ nanowire nanogenerator as selfpowered/active humidity sensor with high sensitivity and fast response. J. Alloys Compounds, 648: 571-576. DOI: 10.1016/j.jallcom.2015.07.035

Zhao, M.H., Z.L. Wang and S.X. Mao, 2004. Piezoelectric characterization of individual zinc oxide nanobelt probed by piezo response force microscope. Nano Lett., 4: 587-590. DOI: 10.1021/n1035198a

Zhu, D., T. Hu, Y. Zhao, W. Zang and L. Xing et al., 2015. High-performance self-powered/active humidity sensing of Fe-doped $\mathrm{ZnO}$ nanoarray nanogenerator. Sensors Actuators B Chem., 213: 382-389. DOI: 10.1016/j.snb.2015.02.119 